\title{
Celebrando os 40 anos do Setor de Educação
}

\author{
Andrea Caldas ${ }^{1}$
}

No ano de 2013, comemoramos os 40 anos do Setor de Educação da Universidade Federal do Paraná (UFPR), herdeiro da Faculdade de Educação, criada em 1971 e transladada, por ato institucional, à condição de Setor no contexto da Reforma Universitária.

Nestes momentos de celebração, de registro simbólico no calendário das datas comemorativas, o sentido da história costuma acentuar-se e nos mobiliza para além de nosso reconhecimento retórico, nos interpelando a responsabilidade temporal.

Eis que então, ao revolver a memória, indagar lembranças, perscrutar fatos e registros, vemo-nos assaltados pela inquietante constatação de que somos, neste tempo e espaço, neste agora, herdeiros de muitas histórias que se plasmaram antes de nós e que se projetam para além deste momento.

Aliás, esta imperiosa relação com os tempos, os pretéritos que se mesclam, se apresentam e vivificam no presente e o futuro que se insinua nos projetos ou na falta deles, nas sementes, nos efeitos esperados ou surpreendidos da nossa ação, é a marca indelével da atividade educativa e, mais ainda, quando esta tarefa é a de formar futuros educadores(as).

Estamos a todo tempo, consciente ou inconscientemente, prosseguindo ações, alicerçando continuidades ou rupturas e lançando sulcos sobre e para as gerações que nos antecederam, acompanhados desde o presente dos conterrâneos do nosso futuro, os estudantes da graduação, da pós-graduação e das escolas, que amanhã serão os novos professores(as) de outras gerações de estudantes. É, pois, do âmago da tarefa deste Setor - o Setor de Educação - revolver a história, projetar existências e movimentar condições.

Ao coletar registros e informações sobre os pioneiros(as) do nosso Setor, ao buscar deslindar o contexto dos idos anos 1970, somos transportados, metaforicamente, para os desafios daquele tempo, os projetos sonhados e as expectativas lançadas. E mais que isto, indagamo-nos se hoje, ao ocuparmos, transitoriamente, este espaço institucional, seja na condição de professores(as),

1 Universidade Federal do Paraná. Curitiba, Paraná, Brasil. R. General Carneiro, nº 460. CEP: 80.060-150. 
técnicos(as) administrativos(as) ou estudantes, prosseguimos com a história, avançamos as tarefas, cumprimos as promessas lançadas e projetadas para o nosso tempo histórico.

Ao buscar os sonhos e projetos das gerações anteriores, e neste olhar sobre aquele presente e sua aliança com este tempo, somos brindados com uma série de registros da atemporalidade de diversas ações.

Destas muitas marcas, gostaria de destacar a relação interdisciplinar do conhecimento e o trânsito entre vários campos de saber. Ou seja, o Setor de Educação não nasce vocacionado para o isolamento, mas ao contrario, alicerça-se numa complexa, rica e por que não dizer, algumas vezes, conflitiva relação com várias áreas de conhecimento, diferentes saberes e visões, concepções epistêmicas e metodológicas. Aqui sempre transitaram variados discursos, profissionais formados em cursos diversos e a incansável busca pela intersecção destes campos.

Este signo da pluralidade, que talvez defina nossa especificidade, num mundo acadêmico, algumas vezes revolvido por dilemas entre paradigmas fechados em si mesmos, já se encontrava registrado no número 1 da Revista da Faculdade de Educação, publicada em 1977, com artigos nas áreas da didática, psicologia, legislação educacional, filosofia, história da educação, administração escolar, arte, sociologia e estudos de gênero.

No editorial deste primeiro periódico, organizado pela professora Porcia Alves, já se anunciava:

para que uma jovem Faculdade de Educação possa se afirmar, adquirir renome e importância é preciso que disponha de meios para isso. Verbas que propiciem e facilitem pesquisas, cursos de aperfeiçoamento e especialização para seus professores, facilidade de intercâmbios com outros centros, veiculo adequado a publicação do que faz e do que pretende fazer. [...] As ideias, hipóteses, conclusões do corpo docente se ampliam, ganham forma e vida ao contacto com outras ideias e pontos de vista. ${ }^{2}$

Eis aqui o registro do compromisso com a pluralidade que delineia o trabalho na Faculdade/Setor de Educação. Mais do que isto, não uma pluralidade meramente interna corporis, mas ancorada em outra importante diretriz, que é a relação com os sistemas de ensino, com a educação básica, com as escolas.

2 ALVES, Porcia. Editorial. Revista de Educação, Curitiba, ano 1, v. 1, n. 1, p. 3, 1977. 
Nosso Setor tem buscado manter e intensificar o compromisso com a pesquisa científica e também com sua socialização e integração com a realidade concreta, tanto como fonte das investigações quanto como espaço de intervenção.

O dilema que parece acometer alguns campos, entre a pesquisa, o ensino e a extensão, entre o rigor acadêmico e o enlaçamento com a vida prática, não se estabeleceu como antítese nas atividades aqui desenvolvidas, senão que como síntese dialética, seja na vigorosa relação com os sistemas de ensino, seja na projeção da pós-graduação.

Também na área das políticas educacionais, desde sempre contamos com o envolvimento de vários docentes e técnicos nas pesquisas associadas aos sistemas de ensino e muitas vezes na atuação diante da condução e gestão dos sistemas de ensino.

Partilhamos da convicção de que os avanços das pesquisas científicas só podem ter papel emancipador quando publicizados, quando propiciam o conhecimento da realidade por muitos, ou seja, com a difusão da ciência que só pode ocorrer com o concurso da elevação da qualidade de educação, que estimule os estudantes ao conhecimento.

A qualidade da educação, destarte, aparece como uma preocupação sempre presente em toda a trajetória do Setor de Educação e que ainda hoje emerge como desafio e inquietação. Será, afinal, que neste quesito não logramos avançar, conquistar, cumprir os desígnios traçados? Frustramos expectativas se miramos o passado, defrontamo-nos com o presente e vislumbramos o futuro?

Pergunta que não admite uma resposta sem contexto, sem cenário, sem compreendermos que é parte intrínseca também da tarefa educativa, a renovada insatisfação, ou dito de outra forma, a criação de novas necessidades a serem enfrentadas, desafiadas. A cada passo caminhado, se inaugura um novo caminho, outro patamar, uma crescente exigência. Quanto mais se aprende, mais se inquieta, mais exigente se fica e, se assim não for, é porque encerrou a ação educativa, deixou-se de desafiar e estimular.

Assim também o é com a educação, vista de modo global. Se não, vejamos, no contexto de criação do Setor de Educação, em 1973, tínhamos no Brasil uma população de 5 a 19 anos de pouco mais de 35 milhões; hoje temos perto de 49 milhões, sendo que dois milhões e seis mil no estado do Paraná.

A matrícula no ensino primário no Brasil, no início da década de 1970, era de 13 milhões e a de ensino médio, perto de cinco milhões, ou seja, tínhamos na educação básica cerca de 18 milhões de estudantes matriculados e hoje temos mais de 50 milhões.

No ensino superior, o crescimento é ainda mais relevante, uma vez que contávamos com 300 mil matrículas neste nível de ensino em todo o país e 
hoje temos perto de seis milhões de estudantes matriculados, sendo 900 mil só na região Sul.

São, portanto, inegáveis os avanços do ponto de vista do acesso à educação, de mudança de perfil societário, geracional e econômico do país. O caminho foi trilhado, passos foram dados, mas que novos caminhos e projetos nos desafiam, agora e sempre.

São novas pessoas a entrar na escola e na universidade, com diferentes perfis e exigências, bem como a própria sociedade e educação modificaram-se, ampliaram seus escopos, diversificaram sua atuação e, com ela, suas expectativas para com nosso trabalho.

Assim, no dizer de Galeano: “A utopia está lá no horizonte. Aproximo-me dois passos, ela se afasta dois passos. Caminho dez passos e o horizonte corre dez passos. Por mais que eu caminhe, jamais alcançarei. Para que serve a utopia? Serve para isso: para que eu não deixe de caminhar"3.

E caminhamos ainda, às vezes tropeçamos por certo, mas temos muitos braços a nos sustentar: os de agora, de companheiros(as) de jornada incerta, desafiadora; os de antes, com os exemplos e os sulcos projetados e conquistados pela sua geração; os de amanhã, presentificados pelos olhares, esperanças e expectativas dos nossos estudantes e dos meninos e meninas nas escolas básicas, nos movimentos sociais, na cidade e no campo.

Contudo, entre tantas coincidências temporais, entre tantos desafios comuns nestes 40 anos, há um elemento de mudança que é preciso ser registrado, de um contexto para outro.

A criação do Setor de Educação, no ano de 1973, encontra um momento político bastante difícil para o país e a universidade. Um tempo onde a necessidade do diálogo, da liberdade de pensamento, tão vitais para a atividade acadêmica, encontrava-se suprimida, constrangida pelo regime de arbítrio instalado no país desde 1964. Um tempo de medo, de desaparecimentos, de prisões arbitrárias, muitas vezes no próprio espaço da universidade. Fertilizar a atividade acadêmica era, pois, muito mais complexo, difícil e perigoso.

No entanto, com a resistência possível alicerçada em alianças sociais, foi possível resgatar as liberdades democráticas que, sabemos, ainda não são tão plenas, num país onde a concentração econômica, o monopólio dos meios de comunicação, as desigualdades sociais e culturais ainda marcam a sociedade, não obstante os avanços.

Mas é preciso, sim, assinalar a diferença entre um tempo e outro, sinalizar as possibilidades e limitações de um período de liberdade, frente a outro

3 GALEANO, Eduardo. As palavras andantes. 4.ed. Trad. Eric Nepomuceno. Porto Alegre: L\&PM, 1994. p. 310. 
de ditadura. Pois, se não o fizermos, estaremos desvalorizando talvez o mais importante legado da geração que nos precedeu.

Hoje nosso desafio não é o de conquistar a democracia como foi outrora, mas o de não deixá-la tornar se habitual, ornamental ou burocrática. É vivificá-la, intensificá-la, celebrar sua conquista a cada dia.

Se relativizarmos a democracia e a liberdade, num raciocínio comodamente niilista, deixamos de ocupar os espaços de diálogo, de construção coletiva, de reuniões, de fóruns de debates, de convivência, matamos um pouco a utopia projetada, renegamos a história de tantos que lutaram duramente antes de nós para que aqui hoje pudéssemos estar, concordando, discordando, escrevendo, publicando, ensinando, aprendendo.

Que saibamos honrar, valorizar e prosseguir este percurso iniciado no Curso de Pedagogia em 1939, sucedida pela Faculdade de Filosofia, e depois o Setor de Educação, que possamos deixar para as novas gerações, não um legado, mas um caminho, uma caminhada e o desejo de prosseguir e superar.

\section{Um último registro}

No evento de comemoração dos 40 anos do Setor de Educação, realizado em outubro de 2013, coube-me a honrosa tarefa de homenagear a primeira diretora do Setor de Educação, professora doutora Zélia Milléo Pavão, e registrar, em nome da comunidade setorial, o agradecimento e reconhecimento pelo trabalho, pela herança, pelo compromisso legado.

Formada em Pedagogia e Matemática pela nossa universidade, com dois pós-doutorados, um na Califórnia e outro em Paris, trouxe na sua gestão marcas bastante significativas para nosso Setor, que ainda hoje fazem parte do nosso projeto institucional como promessas, compromissos e renovados desafios.

Promoveu a intensificação da integração com a educação básica através de convênios com o estado do Paraná e a prefeitura de Curitiba, propiciando inclusive que muitos professores estaduais e municipais viessem atuar na UFPR, em estudos e pesquisas, levantamento e análises de dados sobre a educação paranaense, em todos os municípios do Estado, numa integração com as pesquisas realizadas pela antiga Fundação Educacional do Paraná (Fundepar).

Da mesma maneira, teve atuação destacada na área de política educacional, não só como pesquisadora, mas com o envolvimento na direção do Departamento Estadual de Estatística do Paraná, de 1985 a 1988, onde atuou para transformá-lo em um órgão de informação à sociedade. 
Com trânsito importante nas áreas de educação, matemática e estatística, atuou fortemente na pós-graduação e estabeleceu importantes vínculos entre o ensino, a pesquisa e a extensão.

Desta forma, registramos mais uma vez aqui nosso reconhecimento e gratidão pelo trabalho, a esperança e a persistência desta importante intelectual e sua geração.

Andrea Caldas

Diretora do Setor de Educação

Gestão 2011-2014 